University of San Diego

Digital USD

$1-6-2022$

\title{
Radical-Initiated Brown Carbon Formation in Sunlit Carbonyl-Amine-Ammonium Sulfate Mixtures and Aqueous Aerosol Particles
}

\author{
Natalie G. Jimenez \\ University of San Diego \\ Kyle D. Sharp \\ University of San Diego \\ Tobin Gramyk \\ University of San Diego \\ Duncan Z. Ugland \\ University of San Diego \\ Matthew-Khoa Tran \\ University of San Diego \\ Follow this and additional works at: https://digital.sandiego.edu/chemistry_facpub \\ Se next page for additional authors \\ Part of the Chemistry Commons
}

\section{Digital USD Citation}

Jimenez, Natalie G.; Sharp, Kyle D.; Gramyk, Tobin; Ugland, Duncan Z.; Tran, Matthew-Khoa; Rojas, Antonio; Rafla, Michael A.; Stewart, Devoun; Galloway, Melissa M.; Lin, Peng; Laskin, Alexander; Cazaunau, Mathieu; Pangui, Edouard; Doussin, Jean-François; and De Haan, David O., "Radical-Initiated Brown Carbon Formation in Sunlit Carbonyl-Amine-Ammonium Sulfate Mixtures and Aqueous Aerosol Particles" (2022). Chemistry and Biochemistry: Faculty Scholarship. 41.

https://digital.sandiego.edu/chemistry_facpub/41

This Article is brought to you for free and open access by the Department of Chemistry and Biochemistry at Digital USD. It has been accepted for inclusion in Chemistry and Biochemistry: Faculty Scholarship by an authorized administrator of Digital USD. For more information, please contact digital@sandiego.edu. 


\title{
Radical-Initiated Brown Carbon Formation in Sunlit Carbonyl-Amine-Ammonium Sulfate Mixtures and Aqueous Aerosol Particles
}

\begin{abstract}
Brown carbon $(\mathrm{BrC})$ formed from glyoxal+ammonium sulfate (AS) and methylglyoxal+AS reactions photobleaches quickly, leading to the assumption that $\mathrm{BrC}$ formed overnight by Maillard reactions will be rapidly destroyed at sunrise. Here, we tested this assumption by reacting glyoxal, methylglyoxal, glycolaldehyde, or hydroxyacetone in aqueous mixtures with reduced nitrogen species at $\mathrm{pH} 4-5$ in the dark and in sunlight $(>350 \mathrm{~nm}$ ) for at least $10 \mathrm{~h}$. The absorption of fresh carbonyl+AS mixtures decreased when exposed to sunlight, and no $\mathrm{BrC}$ formed, as expected from previous work. However, the addition of amines (either methylamine or glycine) allowed $\mathrm{BrC}$ to form in sunlight at comparable rates as in the dark. Hydroxyacetone+amine+AS aqueous mixtures generally browned faster in sunlight than in the dark, especially in the presence of $\mathrm{HOOH}$, indicating a radical-initiated $\mathrm{BrC}$ formation mechanism is involved. In experiments with airborne aqueous aerosol containing AS, methylamine, and glyoxal or methylglyoxal, browning was further enhanced, especially in sunlight $(>300 \mathrm{~nm})$, forming aerosol with optical properties similar to "very weak" atmospheric BrC. Liquid chromatography-electrospray ionization-mass spectrometry (LC-ESI-MS) analysis of aerosol filter extracts indicates that exposure of methylglyoxal+AS aqueous aerosol to methylamine gas, sunlight, and cloud processing increases incorporation of ammonia, methylamine, and photolytic species (e.g., acetyl radicals) into conjugated oligomer products. These results suggest that when amines are present, photolysis of first-generation, "dark reaction" BrC (imines and imidazoles) initiates faster, radical-initiated browning processes that may successfully compete with photobleaching, are enhanced in aqueous aerosol particles relative to bulk liquid solutions, and can produce $\mathrm{BrC}$ consistent with atmospheric observations.
\end{abstract}

\section{Keywords}

secondary brown carbon, photosensitization, photobrowning, aqueous SOA, oligomerization, aldehydes

\section{Disciplines}

Chemistry

\section{Notes}

Final published version available at https://doi.org/10.1021/acsearthspacechem.1c00395

\section{Author(s)}

Natalie G. Jimenez, Kyle D. Sharp, Tobin Gramyk, Duncan Z. Ugland, Matthew-Khoa Tran, Antonio Rojas, Michael A. Rafla, Devoun Stewart, Melissa M. Galloway, Peng Lin, Alexander Laskin, Mathieu Cazaunau, Edouard Pangui, Jean-François Doussin, and David O. De Haan 


\section{$1 \quad$ Radical-initiated brown carbon formation in sunlit}

2 carbonyl - amine - ammonium sulfate mixtures and

\section{aqueous aerosol particles}

4 Natalie G. Jimenez, ${ }^{1}$ Kyle D. Sharp, ${ }^{1}$ Tobin Gramyk, ${ }^{1}$ Duncan Z. Ugland, ${ }^{1}$ Matthew-Khoa Tran, ${ }^{1}$

5 Antonio Rojas, ${ }^{1}$ Michael A. Rafla, ${ }^{1}$ Devoun Stewart, ${ }^{1 \dagger \dagger}$ Melissa M. Galloway, ${ }^{1 \dagger}$ Peng Lin, ${ }^{2}$

6 Alexander Laskin, ${ }^{2}$ Mathieu Cazaunau, ${ }^{3}$ Edouard Pangui, ${ }^{3}$ Jean-François Doussin, ${ }^{3}$ David O.

De Haan, ${ }^{1 *}$

9 1: Department of Chemistry and Biochemistry, University of San Diego, 5998 Alcala Park, San Diego CA 92117 USA

11 2: Environmental Molecular Sciences Laboratory, Pacific Northwest National Laboratory,

12 Richland, Washington 99352, USA, now at Department of Chemistry, Purdue University, West

Lafayette IN 47907 USA

14 3: Laboratoire Interuniversitaire des Systèmes Atmosphériques (LISA), UMR7583, CNRS,

15 Université Paris-Est Créteil (UPEC) et Université de Paris, Institut Pierre Simon Laplace (IPSL),

Créteil, France

$17 \dagger$ : now at Department of Chemistry, Lafayette College, Easton PA 18042 USA

$18+\uparrow$ : now at Department of Chemistry, Sacramento City College, 3835 Freeport Blvd.

Sacramento, CA 95822 USA

$21 *$ Corresponding author: ddehaan@sandiego.edu, (619) 260-6882, (619) 260-2211 fax 
22 ABSTRACT: Brown carbon $(\mathrm{BrC})$ formed from glyoxal+ammonium sulfate (AS) and

23 methylglyoxal+AS reactions photobleaches quickly, leading to the assumption that $\mathrm{BrC}$ formed

24 overnight by Maillard reactions will be rapidly destroyed at sunrise. Here we tested this

25 assumption by reacting glyoxal, methylglyoxal, glycolaldehyde or hydroxyacetone in aqueous

26 mixtures with reduced nitrogen species at $\mathrm{pH} 4-5$ in the dark and in sunlight $(>350 \mathrm{~nm})$ for at least

$2710 \mathrm{~h}$. The absorbance of fresh carbonyl+AS mixtures decreased when exposed to sunlight, and no

28 BrC formed, as expected from previous work. However, the addition of amines (either

29 methylamine or glycine) allowed $\mathrm{BrC}$ to form in sunlight at comparable rates as in the dark.

30 Hydroxyacetone+amine+AS aqueous mixtures generally browned faster in sunlight than in the

31 dark, especially in the presence of $\mathrm{HOOH}$, indicating a radical-initiated $\mathrm{BrC}$ formation mechanism

32 is involved. In experiments with airborne aqueous aerosol containing AS, methylamine, and

33 glyoxal or methylglyoxal, browning was further enhanced, especially in sunlight (>300 nm),

34 forming aerosol with optical properties similar to "very weak" atmospheric BrC. LC-ESI-MS

35 analysis of aerosol filter extracts indicates that exposure of methylglyoxal+AS aqueous aerosol to

36 methylamine gas, sunlight, and cloud processing increases incorporation of ammonia,

37 methylamine, and photolytic species (e.g. acetyl radicals) into conjugated oligomer products.

38 These results suggest that when amines are present, photolysis of $1^{\text {st }}$-generation, "dark reaction"

$39 \mathrm{BrC}$ (imines and imidazoles) initiates faster, radical-initiated browning processes that may

40 successfully compete with photobleaching, are enhanced in aqueous aerosol particles relative to

41 bulk liquid solutions, and can produce $\mathrm{BrC}$ consistent with atmospheric observations. 


\section{Introduction}

43 Aerosol particles negatively impact human health, ${ }^{1-8}$ and aerosol particles that absorb light,

44 such as brown carbon $(\mathrm{BrC})$, also exacerbate climate change. ${ }^{9-18}$ Determining ways to limit

45 atmospheric $\mathrm{BrC}$ concentrations is desirable on both accounts. While a majority of brown carbon

46 is emitted directly from incomplete combustion (primary BrC), about a third is formed in the

47 atmosphere via poorly-characterized reactions in the gas or aqueous phase. ${ }^{19,20}$ Significant

48 amounts of secondary $\mathrm{BrC}$ are thought to be formed by aqueous Maillard reactions involving

49 closed-shell reactions of small, water-soluble carbonyl species with ammonium or amine salts, ${ }^{21-}$

$50 \quad{ }^{27}$ producing imine intermediates ${ }^{28}$ which oligomerize to form light-absorbing species (the "imine

51 pathway"), ${ }^{29-33}$ and by aqueous photo-oxidation of phenolic species, ${ }^{34-40}$ especially when catalyzed

52 by $\mathrm{Fe}(\mathrm{III})$ ions. ${ }^{41-43}$ Co-oxidation of glyoxal and dissolved $\mathrm{SO}_{2}$ has also been recently shown to

53 form $\mathrm{BrC}^{44}$ The relative importance of these various $\mathrm{BrC}$ formation pathways in the atmosphere

54 has not been determined.

$55 \mathrm{BrC}$ in the atmosphere is subject to aging processes which are even less understood than $\mathrm{BrC}$

56 formation. ${ }^{45-51}$ Light-absorbing molecules may be destroyed by hydroxyl radicals or other oxidant

57 species that diffuse into the aqueous phase or are formed in situ. ${ }^{48}$ Photobleaching of BrC may

58 also occur, triggered by direct light absorption $27,43,45$ or indirectly via reaction with

59 "photosensitizer" species. ${ }^{52-54}$ Rapid photobleaching of $\mathrm{BrC}$ formed in mixtures of glyoxal or

60 methylglyoxal with AS has been observed in several studies performed in bulk-phase solution. ${ }^{55-}$

6159 In some more complex systems, photolysis, photooxidation, or oxidation by radical species can

62 at least temporarily increase $\mathrm{BrC}$ formation, ${ }^{54,57,60,61}$ especially in evaporating droplets. ${ }^{32}$ In the

63 vast majority of these studies, $\mathrm{BrC}$ is formed in the dark, then photolyzed or photooxidized

64 separately, simulating a diurnal cycle, guided by an implicit assumption that BrC forms at night 
65 and is destroyed during the day. This two-step experimental design, however, does not address

66 the extent to which $\mathrm{BrC}$ might form in the sunlit atmosphere, perhaps aided by radical-initiated

67 reactions. Experimental photobleaching results are also dependent on photolysis wavelengths,

68 highlighting the importance of simulating the solar spectrum in laboratory simulations of 69 photobleaching.

70 In this work, we study the effects of sunlight and an $\mathrm{OH}$ radical source (hydrogen peroxide,

$71 \mathrm{HOOH})$ on aqueous-phase $\mathrm{BrC}$ formation involving reactions of glyoxal (GX), methylglyoxal

72 (MG), hydroxyacetone (HA), and glycolaldehyde (GAld) with ammonium sulfate, glycine, and

73 methylamine in order to determine whether daytime radical-initiated mechanisms play a

74 significant role.

75

\section{Methods}

77 Bulk-phase studies. The initial UV/vis absorption spectra of bulk phase aqueous reaction

78 mixtures ( $0.25 \mathrm{M}$ of each reactant, $\mathrm{pH}$ set to 4 with oxalic or sulfuric acid) were recorded with 2

$79 \mathrm{~nm}$ spectral resolution over the range $200-800 \mathrm{~nm}$ using $1 \mathrm{~cm}$ quartz cuvettes in a diode array

80 absorption spectrometer (HP8452A). Each reaction mixture was then placed in a capped Pyrex

81 vial with a $50 \%$ transmittance cutoff of $\sim 350 \mathrm{~nm}$, and the set of vials were exposed to ambient

82 midday sunlight for $4 \mathrm{~h}(\sim 12-4 \mathrm{pm}$ on days with little or no cloud coverage in San Diego,

83 California, day-to-day solar intensity varied by $\sim 30 \%$ ). A matching set of solutions were placed

84 in most experiments at the same location under aluminum foil so that they would react in the dark

85 at comparable temperatures. Temperature monitoring of select vials indicated that dark and sunlit

86 samples remained within $3{ }^{\circ} \mathrm{C}$ of each other, unless specified otherwise. After the 4-h reaction

87 time, the UV/vis spectra of the contents of each vial were recorded and the samples were stored in 
88 the dark at $4{ }^{\circ} \mathrm{C}$ until the next day. The process was repeated for at least two subsequent days for

89 each vial. Minimal spectral changes were observed during overnight cold storage. The initially

90 measured absorbance spectrum for each mixture was subtracted from subsequently measured

91 spectra to generate $\triangle A b s$ difference spectra, to show the change in absorbance during sample aging.

92 Absorbance changes were converted to mass absorption coefficients changes $(\triangle M A C)$ by the

93 following equation:

94

$$
\Delta M A C=\frac{\ln (10) \Delta A b s}{b C_{\text {org }}}
$$

95 where $b$ is the pathlength in $\mathrm{cm}$ and $C_{\text {org }}$ is the sum of the concentrations of the carbonyl reactant

96 species and the amine species (if any) in the reaction mixture in $\mathrm{g} \mathrm{cm}^{-3}$. The Angstrom absorbance

97 exponents (AAE) were also characterized by power law fits to absorbance spectra in the range 330

$98-400 \mathrm{~nm}$. This fit range was adjusted to longer wavelengths by up to $50 \mathrm{~nm}$ when necessary to

99 avoid saturated absorbance readings (Abs $>2.0$ ).

100 Aerosol studies. Mixtures of carbonyls, AS, and amines (0.056 M of each reactant) were

101 aspirated into a $300 \mathrm{~L}$ Tedlar chamber. The airborne aerosol particles were then aged for $1 \mathrm{~h}$ in

102 midday ambient sunlight, or indoors away from sunlight in control experiments. After $1 \mathrm{~h}$ of

103 aging, aerosol particles were collected onto Teflon filters, which were then extracted in $10 \mathrm{~mL}$

104 deionized water $(>18 \mathrm{M} \Omega)$. The absorbance of filter extracts was analyzed by diode array

105 absorption spectroscopy (HP8452A) in $1 \mathrm{~cm}$ cuvettes. $\triangle M A C$ values were calculated using $C_{\text {org }}$

106 calculated from the mass increase of the filter during sampling divided by the extraction volume;

107 AAE fits were determined as described above.

108 Simulation chamber experiment / high-resolution MS analysis. $100 \mathrm{mM} \mathrm{MG}$ and $10 \mathrm{mM}$ AS /

$10930 \mathrm{mM}$ MG solutions were atomized (TSI 3076) and, for control experiments, $100 \mu \mathrm{g}$ of diffusion- 
110 dried aerosol was immediately collected onto teflon filters (Tisch, $1.0 \mu \mathrm{m}$ pore size) without any

111 chamber exposure time. The same AS+MG mixture was also atomized without diffusion drying

112 into the humidified, $4.2 \mathrm{~m}^{3}$ CESAM chamber, which has been described earlier. ${ }^{62,63}$ There, these

113 deliquesced seed particles were exposed to $2 \mathrm{ppm}$ methylamine gas, 80 minutes of simulated

114 sunlight, and 1-2 cloud events of 5 to $10 \mathrm{~min}$. duration each, triggered by a combination of water

115 vapor injection and a gradual, 10\% pressure reduction to reach supersaturation. Chamber

116 experimental conditions are summarized in Table S1. After processing in the chamber concluded,

117 aerosol were collected onto Teflon filters at a flow of $15 \mathrm{~L} / \mathrm{min}$ over $16 \mathrm{~h}$, while chamber pressure

118 was held constant with a compensating flow of dry nitrogen, resulting in a continuous reduction

119 in RH during sampling. All filters were kept frozen at $-20 \mathrm{C}$ until extraction by acetonitrile and

120 analysis using a HPLC/PDA/HRMS platform. ${ }^{64}$ The instrument consists of a Surveyor Plus

121 system (including HPLC pump, autosampler and PDA detector), a standard IonMAX electrospray

122 ionization (ESI) source, and a high resolution LTQ-Orbitrap mass spectrometer (all modules are

123 from Thermo Electron, Inc.). Details about the experimental setup, data acquisition, peak

124 deconvolution, and molecular formula assignment have been described previously. ${ }^{31}$ Exact masses

125 detected for peaks with areas greater than $10^{6}$ and elevated relative to blank extract runs are

126 reported here.

127

128 Results and Discussion

129 Carbonyl + AS mixtures. Changes in absorbance (expressed as $\triangle M A C$ ) of aqueous mixtures

130 containing $0.25 \mathrm{M}$ carbonyl compounds and 0.25 M AS reacting for 10-14 h are shown in Figure

131 1. (See Figure $S 1$ for corresponding $\triangle A b s$ graph.) Under dark conditions (green lines), the relative

132 levels of browning observed, MG >> GX > GAld HA, matches previous observations. ${ }^{65}$ In fact, 
133 MAC increases at wavelengths below $400 \mathrm{~nm}$ in MG+AS and GX+AS mixtures after $6 \mathrm{~h}$ are quite

134 similar to those reported after 4 days at the same $\mathrm{pH}$ and concentrations, ${ }^{65}$ indicating that UV-

135 absorbing reaction products form in these mixtures in hours rather than days under these

136 conditions. In HA+AS and GAld+AS mixtures, however, significant browning is not observed at

137 any wavelength even after $14 \mathrm{~h}$ of reaction time. Figure 1 shows that MAC increases in the visible

138 range $(>400 \mathrm{~nm})$ remains negligible $\left(<5 \mathrm{~cm}^{2} \mathrm{~g}^{-1}\right)$ in all samples through $14 \mathrm{~h}$ of reaction time.

139 Visible browning - the development of an absorbance "tail" extending to wavelengths beyond 400

$140 \mathrm{~nm}-$ is quite slow in acidified bulk aqueous samples, developing only after a few days of reaction

141 time. ${ }^{23,25,65}$

142 The effects of sunlight on duplicate reaction mixtures are shown in Figure 1 (gold lines). During

143 the initial $2 \mathrm{~h}$ of photolysis, the overall absorbance of the GX+AS and MG+AS samples declined.

144 Clearly, no $\mathrm{BrC}$ is forming in sunlight, validating the conclusion of other studies that $\mathrm{BrC}$ formed

145 overnight by dark GX+AS and MG+AS reactions would be rapidly destroyed during the day. $.57,58$

146 Indeed, BrC formed by dark $\mathrm{GX}+\mathrm{AS}$ and $\mathrm{MG}+\mathrm{AS}$ reactions has been shown to photobleach

147 rapidly, with a lifetime on the order of minutes, ${ }^{55-58}$ much faster than its slow formation over hours

148 in bulk samples, even at slightly elevated temperatures here. For GX and MG, MAC declines in

149 sunlight in Figure 1 are strongest at wavelengths where the most browning occurred in the dark,

150 producing $\triangle M A C$ spectra that look like negative mirror images of those recorded under dark

151 conditions. Declining absorbance observed in sunlight indicates a loss of reactants (or loss of

152 rapidly-formed products already present in the initial $t=0$ absorbance measurement) due to direct

153 photolysis or reactions with photosensitizers. 


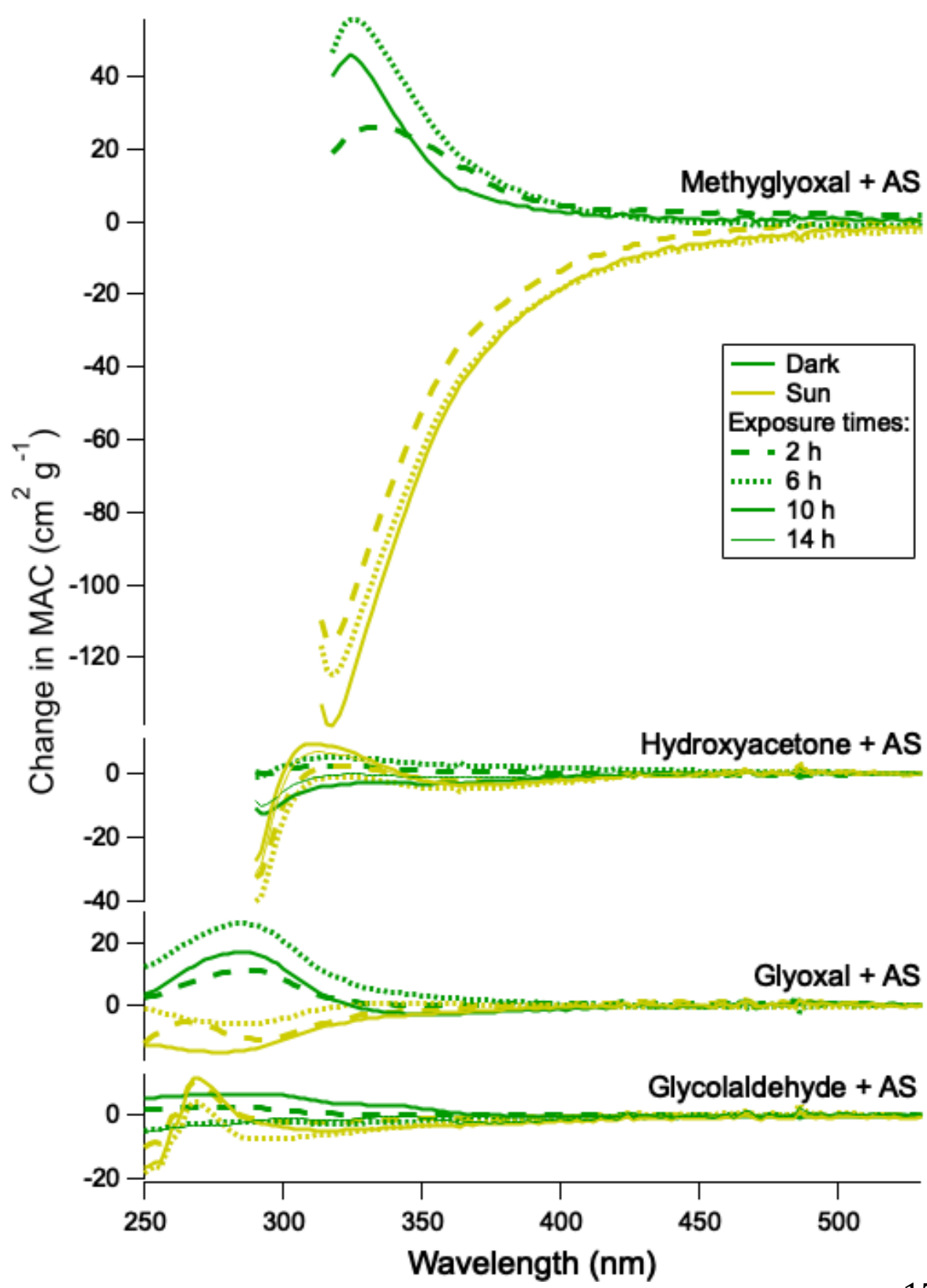

Figure 1: Changes in wavelength-dependent mass absorption coefficients (MAC) of aqueous reaction mixtures containing $0.25 \mathrm{M}$ carbonyl compound and $0.25 \mathrm{M}$ ammonium sulfate after varying times of dark reaction at $21-28$ ${ }^{\circ} \mathrm{C}$ (green lines) or reaction in sunlight at 23-35 ${ }^{\circ} \mathrm{C}$ (gold lines). All data is shown on equivalent vertical scale; gaps in data 171 indicate off-scale

172 absorbance readings, such that MAC changes cannot be calculated accurately. Reaction times are 173 indicated by line type: $2 \mathrm{~h}$ (dashed line), 6h (dotted line), 10h (thick solid line), and 14h (thin line, 174 GAld and HA only). Color indicates sunlit (gold) or dark (green) conditions). 
176 For GAld+AS and HA+AS reaction mixtures (which did not brown significantly during $14 \mathrm{~h}$

177 in the dark), the effects of sunlight are subtle and wavelength-dependent. Sunlight caused the

178 absorbance of the GAld+AS sample to decrease at most wavelengths, but also caused an

179 absorbance band centered at $270 \mathrm{~nm}$ to appear. Similarly, sunlight caused an absorbance band at

$180312 \mathrm{~nm}$ to increase in the HA+AS sample. Each of these bands increased in height by only $\leq 12$

$181 \mathrm{~cm}^{2} \mathrm{~g}^{-1}$ (+0.08 absorbance units) during $10 \mathrm{~h}$. In contrast, absorbance did not increase at any

182 wavelength in sunlit MG+AS and GX+AS mixtures.

183 Carbonyl + amine + AS mixtures. It is sometimes suggested that the rapid photobleaching of

$184 \mathrm{MG}+\mathrm{AS}$ and GX+AS mixtures can be generalized to all imine-based brown carbon systems. The

185 validity of this inference was tested in experiments where carbonyl compounds reacted with

186 AS+glycine and AS+methylamine mixtures (Figures 2, S2, and S3). 


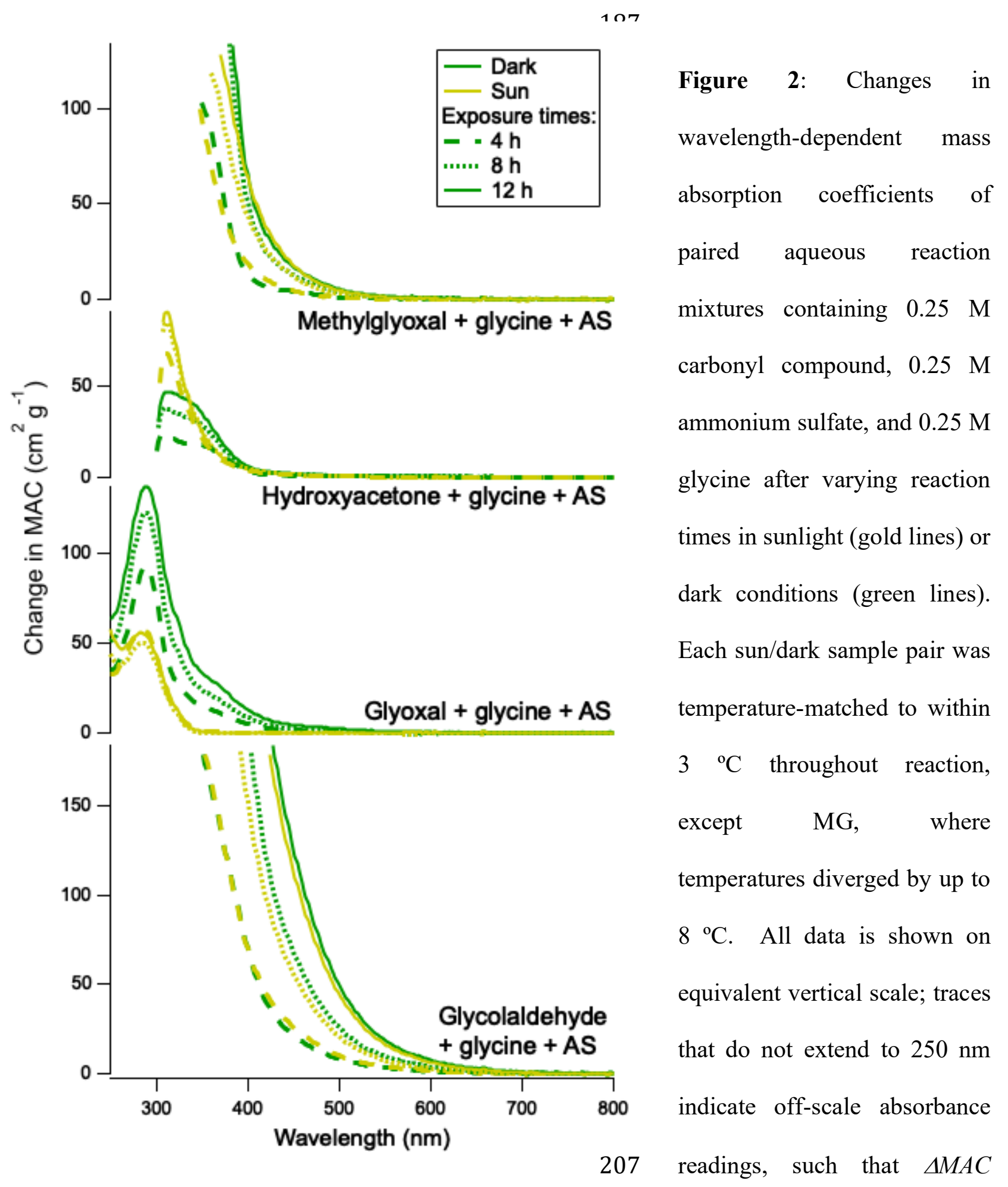

208 cannot be calculated accurately. Reaction times indicated by line type: $4 \mathrm{~h}$ (dashed), $8 \mathrm{~h}$ (thick 
209 dotted), $12 \mathrm{~h}$ (solid). Color indicates sunlit (gold) or dark (green) conditions). See Figure S2 for 210 corresponding $\triangle A b s$ graphs.

211 The addition of an amine to the mixtures profoundly changes their browning behavior in the

212 dark and especially in the sun, even though $\mathrm{pH}$ is held constant. In the dark, UV absorbance is

213 intensified by amine addition in all four reaction mixtures, as observed in previous studies. ${ }^{65,66}$

214 Absorbance clearly extends into the visible range for GX, MG and GAld+glycine+AS solutions

215 after a few hours reaction time. In sunlight, the presence of glycine counteracts the photobleaching

216 of starting materials that was observed in carbonyl+AS solutions. Instead, absorbance now

217 increases under both dark and sunlit conditions for all carbonyl+glycine+AS solutions. With

218 GX+glycine+AS, the magnitude of the absorbance increase is less in sunlight than in the dark,

219 indicating that photobleaching is occurring but cannot keep pace with $\mathrm{BrC}$ production. The same

220 is true with $\mathrm{HA}+$ glycine+AS at wavelengths $>335 \mathrm{~nm}$. Browning in sunlight and in the dark is

221 nearly identical for MG and GAld+glycine+AS solutions, suggesting that either the BrC products

222 are resistant to photolytic degradation or that rates of photobleaching and an additional

223 photolytically-activated browning process are nearly balanced. Generally similar browning

224 behavior was observed using methylamine rather than glycine as the amine species (Figure S3).

225 Methylamine-containing mixtures browned in sunlight for $12 \mathrm{~h}$, but more slowly than in the dark

226 for MG, GAld (> $340 \mathrm{~nm}$ ), and GX+methylamine+AS (> $300 \mathrm{~nm}$ ) reaction mixtures, which

227 suggests that photobleaching is slower than $\mathrm{BrC}$ production in these systems.

228 The extreme differences between sunlit browning in carbonyl+amine+AS mixtures and rapid

229 photobleaching in carbonyl+AS mixtures demonstrate that the effects of sunlight on $\mathrm{BrC}$ formation

230 and photobleaching cannot be generalized across imine-based $\mathrm{BrC}$ reaction systems. These bulk- 
231 phase experiments show that carbonyls can form $\mathrm{BrC}$ even in the daytime atmosphere if they are

232 present with amines in aqueous aerosol particles at high enough concentrations.

233 In contrast to the three aldehydes tested, the ketone species HA unexpectedly browned faster in

234 sunlight than in the dark when mixed with AS and an amine species, especially at wavelengths

235 below $350 \mathrm{~nm}$. This indicates the existence of a fast browning mechanism initiated by a radical

236 or photosensitizer species. This "photobrowning" was observed below $350 \mathrm{~nm}$ in 5 out of 8

237 replicate experiments on $\mathrm{HA}+$ methylamine+AS mixtures (Figure $\mathrm{S} 4$ ) including all three runs

238 where methylamine was acidified with sulfuric acid. In other runs, acidifying to the same $\mathrm{pH}$ with

239 oxalic acid unexpectedly ${ }^{67}$ enhanced the dark browning of these mixtures without having a

240 consistent effect on sunlit samples. Within each acidification group (using sulfuric or oxalic acid),

241 while the absorbance that developed in dark HA+methylamine+AS mixtures varied from

242 experiment to experiment, likely due to day-to-day temperature variation, sunlit experiments

243 exhibited a larger variation in absorbance. This higher variation in photobrowning may be caused

244 by the additional variable of solar intensity, and/or by an important role of some photolytically-

245 active species in the mixture, such as a photosensitizer first-generation product or trace oxidant

246 precursor absorbed from the air when the reaction vial is opened. We explore the role of one such

247 oxidant precursor species, hydrogen peroxide, in the next section.

248 Effects of $\mathrm{HOOH}$ on $\mathrm{BrC}$ formation. Figure 3 summarizes the effects of two different

249 concentrations of $\mathrm{HOOH}$ for $\mathrm{HA}+$ methylamine+AS mixtures in the dark and in sunlight. In the

250 dark, the addition of $\mathrm{HOOH}$ (light and dark blue lines) suppresses the buildup of light-absorbing

251 products, especially at higher $\mathrm{HOOH}$ concentrations (dark blue lines), likely due to direct oxidation

252 of BrC species. High concentrations of $\mathrm{HOOH}$ initially suppress the accumulation of $\mathrm{BrC}$ species

253 in sunlight, too (dark red lines), but after a few hours BrC formation accelerates and eventually 
254 overtakes that of $\mathrm{HOOH}$-free samples. Since $\mathrm{HOOH}$ is slowly being photolyzed by sunlight and

255 converted to $\mathrm{OH}$ radicals, we hypothesize that the initial large excess of $\mathrm{HOOH}$ rapidly destroys

$256 \mathrm{BrC}$ products as they form, as seen in dark samples, while $\mathrm{OH}$ radicals trigger $\mathrm{BrC}$ production

257 reactions that are faster than, and distinct from, the dark pathways involving only closed-shell

258 reactants. Thus, it is only when most excess $\mathrm{HOOH}$ is used up that radical-initiated brown carbon

259 products can rapidly accumulate. Furthermore, the similarity of absorbance spectra in all sunlit

260 samples after $12 \mathrm{~h}$ reaction times is consistent with some baseline level of $\mathrm{OH}$ radical production

261 in $\mathrm{HOOH}-$ free samples from photosensitization by starting materials or first-generation products. ${ }^{68}$

262 The hypothesis that $\mathrm{OH}$ catalyzes rapid brown carbon production in HA+amine+AS mixtures

263 while excess $\mathrm{HOOH}$ destroys brown carbon was supported by experiments where the timing and

264 amounts of $\mathrm{HOOH}$ added and the amine species were varied. With 10x less initial $\mathrm{HOOH}$ added

265 (Figure 3), some suppression of browning was still observed in the dark (light blue lines), but

266 rapid browning in sunlight (orange lines) started immediately, without the initial induction period

267 seen with higher $\mathrm{HOOH}$ concentrations. In other experiments, $0.25 \mathrm{M} \mathrm{HOOH}$ was added not only

268 at $\mathrm{t}=0$ but also at 4,8 , and $12 \mathrm{~h}$ (Figure S6) to test the effects of replenishing excess HOOH. In

269 these experiments, no significant browning was observed, and some photobleaching occurred

270 below $325 \mathrm{~nm}$, further supporting the idea that excess $\mathrm{HOOH}$ destroys brown carbon or its

271 precursors.

272 Similar results were observed in experiments where methylamine was replaced with glycine

273 (Figure S7). Although absorbance increased more slowly at $350 \mathrm{~nm}$ with glycine, the most brown

274 carbon still formed when solutions containing lower levels (0.025 M) of $\mathrm{HOOH}$ were exposed to

275 several hours of sunlight. Clearly sunlight and especially $\mathrm{OH}$ radicals enhance $\mathrm{BrC}$ production in 
$276 \mathrm{HA}+\mathrm{amine}+\mathrm{AS}$ reaction mixtures, pointing to the importance of radical-initiated $\mathrm{BrC}$ formation 277 pathways in this reaction system. 


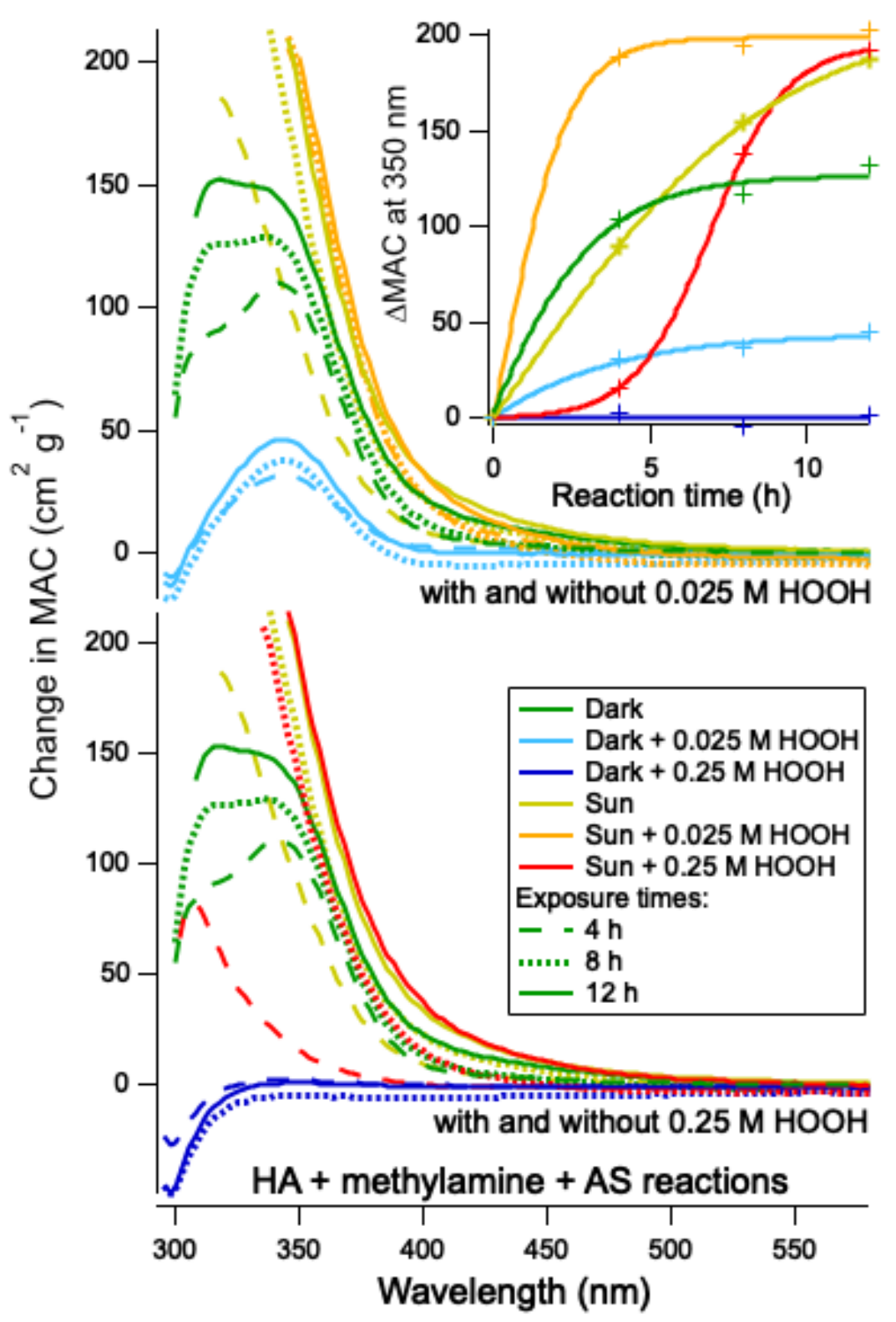

Figure 3: Changes in wavelength-dependent mass absorption coefficients of paired reaction mixtures containing $0.25 \mathrm{M} \mathrm{HA}$, methylamine, and AS in sunlight (gold) or dark (green) after $4 \quad \mathrm{~h}$ (dashed lines), $8 \mathrm{~h}$ (dotted lines), or $12 \mathrm{~h}$ (solid lines). Top panel: comparison with identical mixtures with $0.025 \mathrm{M} \mathrm{HOOH}$ in sunlight (orange) or in dark (light blue).

296 Lower panel: comparison with identical mixtures with $0.25 \mathrm{M} \mathrm{HOOH}$ in sunlight (red) or in dark

297 (dark blue). Inset: $\triangle M A C$ at $350 \mathrm{~nm}$ vs time, using same color code. See Figure S5 for 298 corresponding $\triangle A b s$ graphs.

300 Carbonyl + amine + AS aerosol particles. Since absorption spectra ${ }^{50}$ and browning chemistry 301 can differ in suspended aerosol particles from that in bulk solutions, ${ }^{32}$ aqueous aerosol particles 
302 were generated in Tedlar bags and exposed to either in full-spectrum sunlight or ambient indoor

303 light while suspended in air, before filtration and extraction. The mass absorption coefficients

304 (MAC) of filter extracts from suspended aerosol experiments are summarized in Figure 4. For the

305 GX + methylamine + AS system (top panel), aerosol-phase browning between 300 and $400 \mathrm{~nm}$ is

306 more pronounced when particles are aged in sunlight rather than indoor ambient light, with or

307 without added $\mathrm{HOOH}$. This is the opposite of what is observed at these wavelengths when bulk

308 solutions are exposed to sunlight (Figure S3, $3^{\text {rd }}$ panel), demonstrating that photolytically-driven

309 radical reactions can produce $\mathrm{GX}$-derived $\mathrm{BrC}$ material in sunlight, not just at night, at enhanced

310 rates in suspended aqueous aerosol particles compared to bulk liquid samples. While the addition

311 of $1.7 \mathrm{mM} \mathrm{HOOH}$ to the aerosol-generation liquid suppressed $\mathrm{BrC}$ formation to some extent in

312 both sunlight and indoor experiments, the $1 \mathrm{~h}$ photolysis time in these experiments may have been

313 insufficient to eliminate excess $\mathrm{HOOH}$. In any case, sunlit samples still browned more than dark

314 samples in the presence of $\mathrm{HOOH}$. 


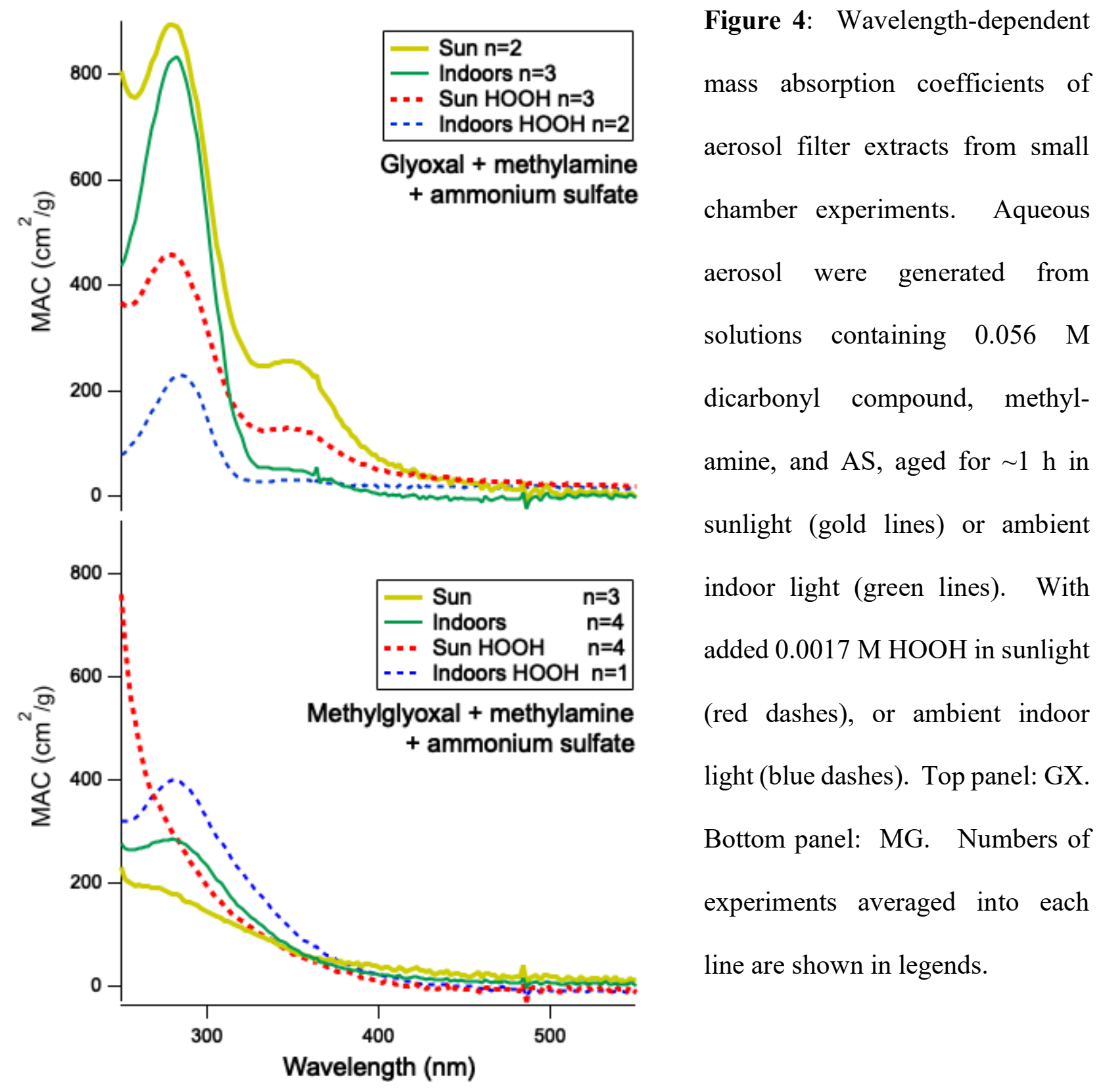

333

334 For MG+methylamine+AS aerosol, slightly more browning is observed in particles protected

335 from sunlight than in those exposed to sunlight (Figure 4 bottom panel), even in the presence of $336 \mathrm{HOOH}$, but the difference is smaller than in bulk solutions (Figure S3, $1^{\text {st }}$ panel). Taken together, 337 these results for dicarbonyl+methylamine+AS solutions suggest that photosensitization / radical- 
338 induced browning can be enhanced in aerosol particles relative to bulk liquid solutions with the

339 same reactants present. This is important because most $\mathrm{BrC}$ photobleaching studies to date have

340 been performed on bulk liquid solutions, ${ }^{55-59}$ even if the brown carbon was initially formed in

341 suspended aerosol. ${ }^{58}$

342 The optical parameters of $\mathrm{BrC}$ from each experiment are compared to the recent atmospheric

343 BrC classification scheme of Saleh et al. ${ }^{69,70}$ in Figure 5. It can be seen that $\mathrm{BrC}$ formed in dark,

344 bulk-phase reactions between carbonyl species and AS (black triangle) does not match

345 atmospheric $\mathrm{BrC}$ in absorptivity, expressed as $\log \left(\mathrm{MAC}_{405}\right)$, and on average has a wavelength

346 dependence (expressed as $\mathrm{AAE}_{330-400}$ ) that is steeper. (Since no $\mathrm{BrC}$ forms from this system in

347 sunlight, this condition cannot appear in Figure 5.) The addition of an amine species to bulk-phase

348 carbonyl-AS mixtures brings the wavelength dependence of absorption into the range of very weak

$349 \mathrm{BrC}$ and allows brown carbon to form in the sun, but the average MAC values are still lower than

350 atmospheric BrC. MAC values extracted from aerosol-phase experiments are higher than in bulk-

351 phase experiments, especially in experiments where suspended aerosol were exposed to $1 \mathrm{~h}$ of

352 sunlight. Under these sunlit aerosol conditions, the $\mathrm{BrC}$ formed from carbonyl+AS+amine

353 reactions, on average, matched the wavelength dependence and absorptivity of the "very weak"

354 class of $\mathrm{BrC}$ observed in the atmosphere. 


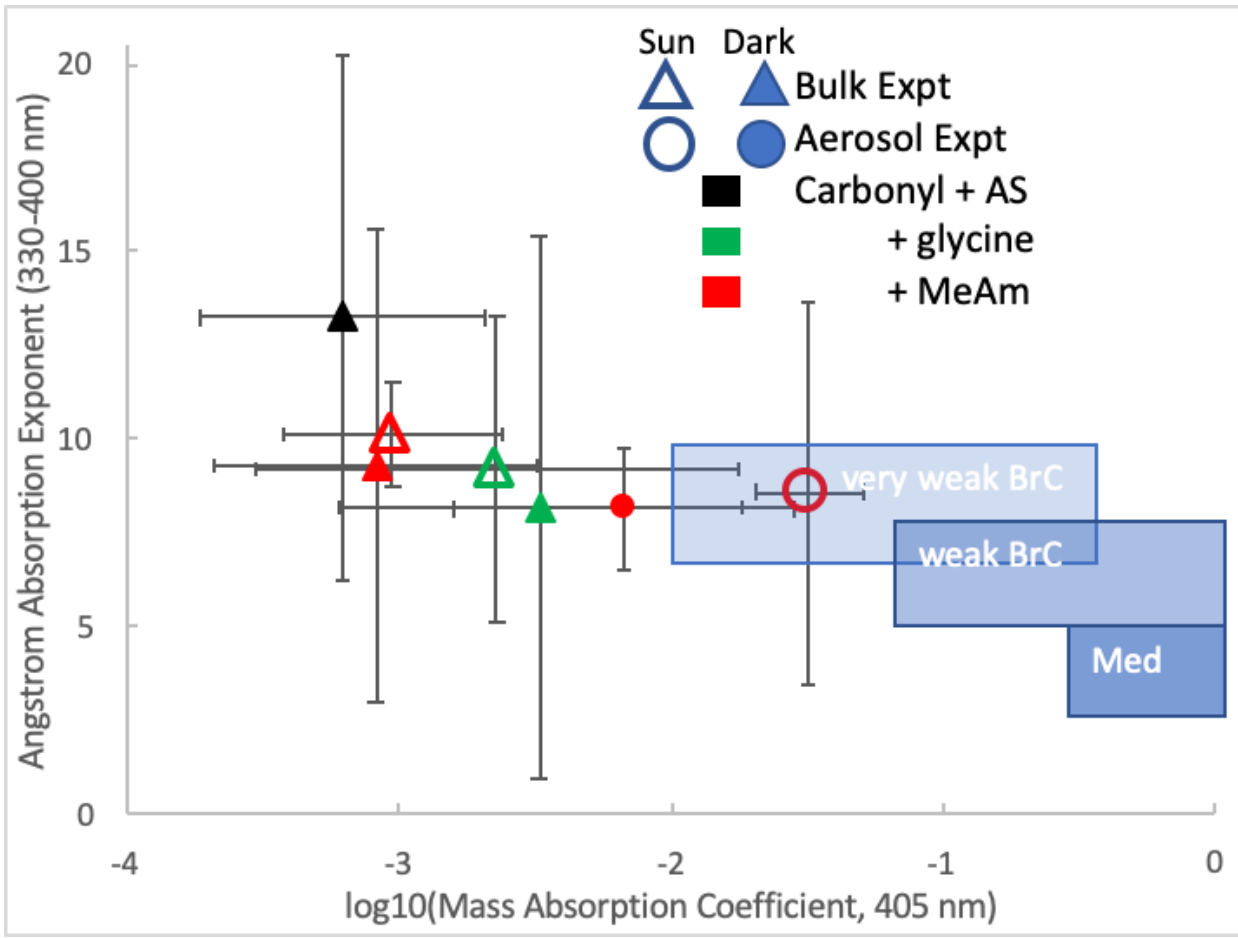

356 Figure 5: Optical parameters of $\mathrm{BrC}$ formed in this study compared to Saleh's field-based BrC

357 classification scheme, graphed as Angstrom absorption exponent vs MAC405. Each data point

358 represents an average of experiments with different carbonyl compounds; shapes indicate bulk

359 phase (triangle) or aerosol phase (round) experiments, while fill indicates dark (filled) or sunlit

360 (open symbol) conditions. All experiments contain carbonyl species and ammonium sulfate.

361 Symbol color indicates amine present: no amine (black), methylamine (red), or glycine (green).

363 Chemical analysis of aerosol particles. Additional MG+methylamine+AS experiments with

364 offline LC-ESI-MS analysis were conducted in the CESAM chamber to further our mechanistic 365 understanding of the photolytic browning pathway involving amines. In these experiments we 366 compared pure MG seed aerosol particles and 3:1 MG:AS seed aerosol particles with no chamber 367 exposure to 3:1 MG:AS aerosol particles that had been exposed to 2 ppm methylamine gas, 80 368 minutes of simulated sunlight, and cloud processing in the chamber. A list of observed ions with 
369 exact masses, peak area ranking, minimum light/dark experiment peak area ratios, and proposed

370 molecular formulae, structures, and precursor species is shown in Table 1. Product molecules

371 detected only with chamber exposure to methylamine and sunlit clouds are labeled "unique," while

372 remaining products are listed in order from most increased to most decreased due to chamber

373 exposure.

374

375 Table 1: Changes in Reaction Products Detected in Methylglyoxal+AS Aerosol Particles Upon

376 Exposure to Methylamine Gas, Simulated Sunlight, and Cloud Processing

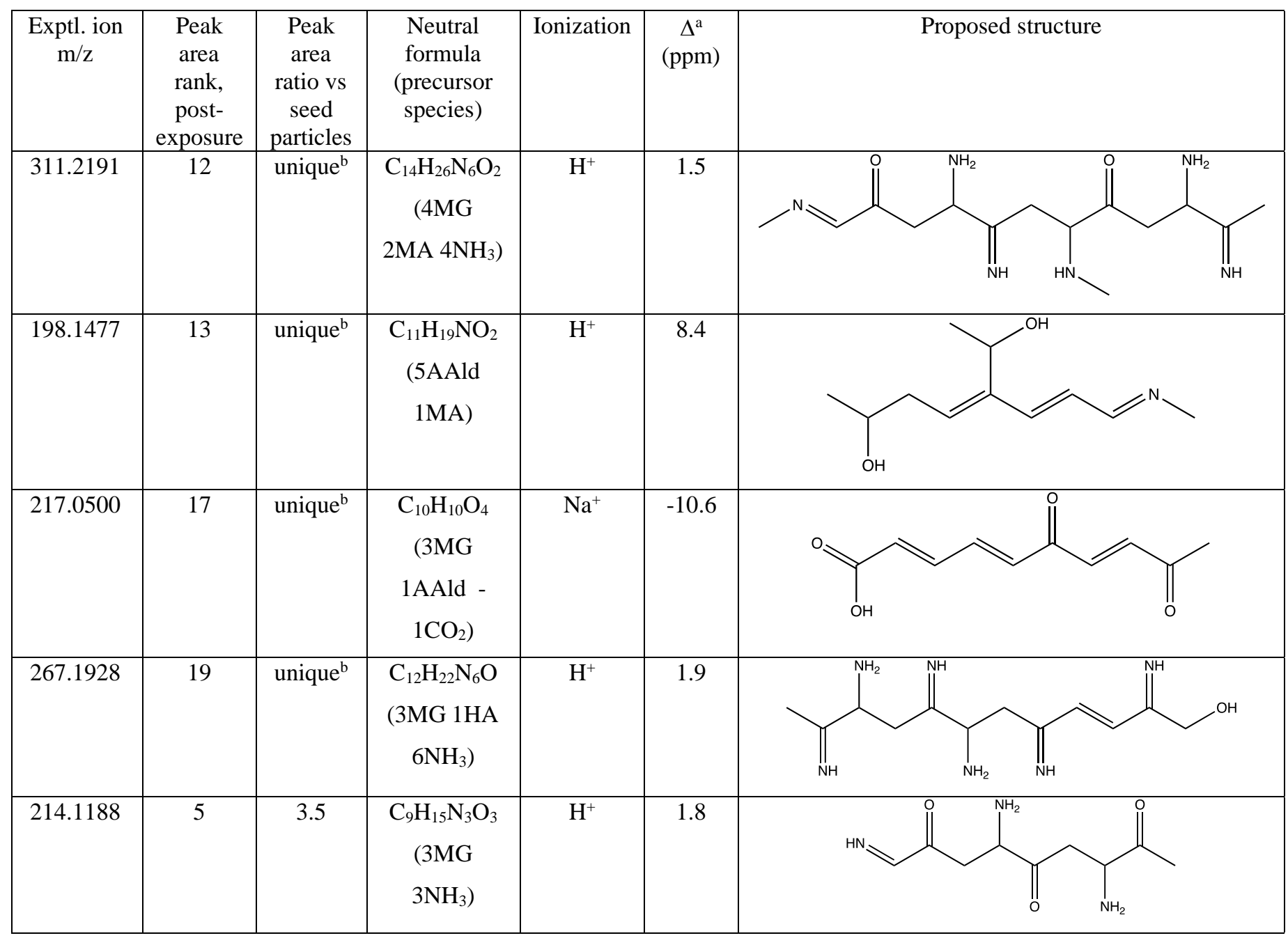




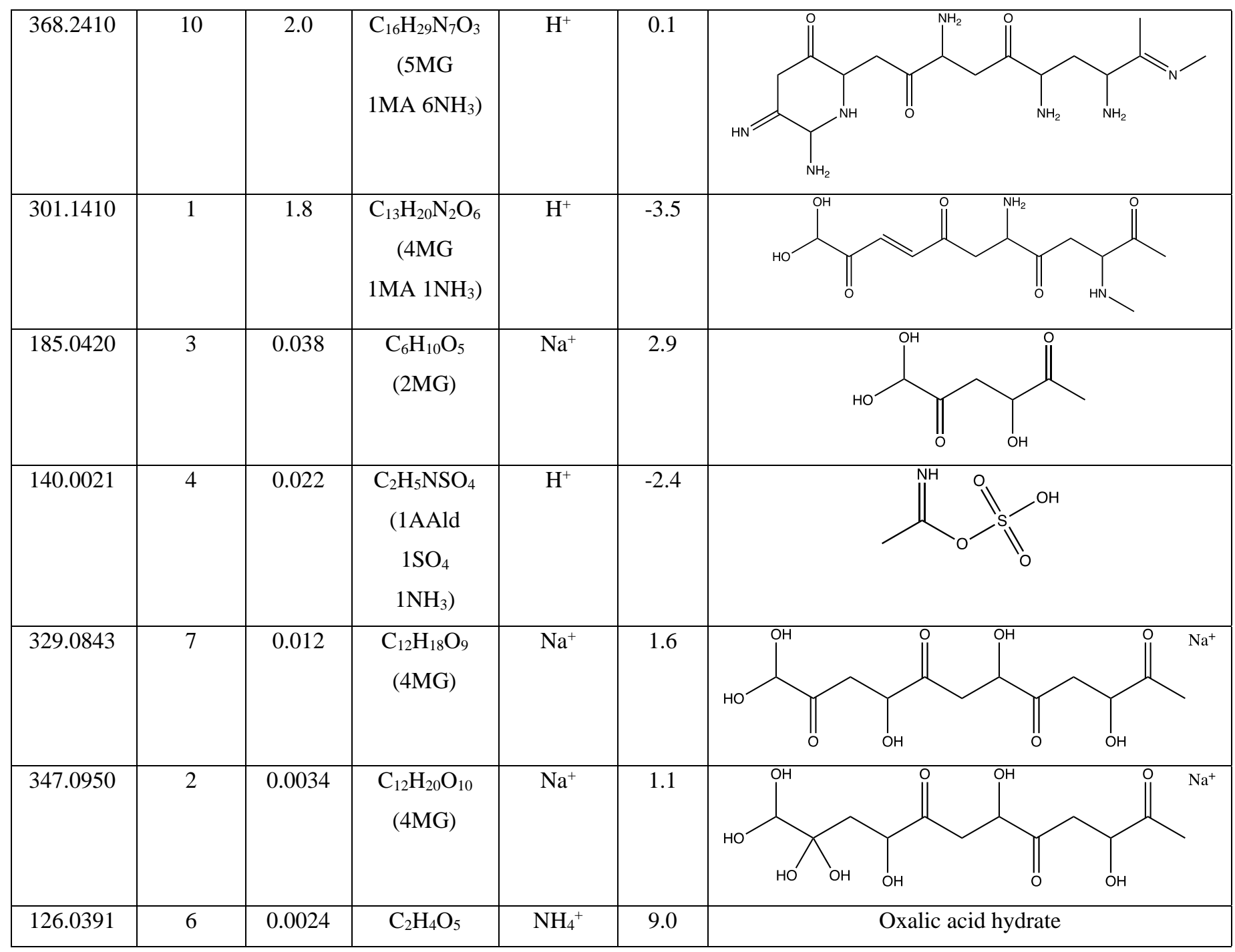

377 Seven peaks detected by positive ion mode ESI-MS that increased in sunlight are listed, followed 378 by the five largest peaks that decreased in sunlight (ratio $<1$ ), listed in order of decreasing light379 to-dark experiment peak area ratios. Molecular formulas were detected as $\mathrm{H}^{+}$adducts unless 380 otherwise stated. Abbreviations: $\mathrm{MG}=$ methylglyoxal. $\mathrm{MA}=$ methylamine. $\mathrm{NH}_{3}=$ ammonia. 381 AAld $=$ acetaldehyde or acetyl radical. $-1 \mathrm{CO}_{2}=$ photolytic decarboxylation. $\mathrm{HA}=$ 382 hydroxyacetone, formed from $\mathrm{MG}$ photolysis. $\mathrm{SO}_{4}=$ sulfate ion. a: nominal - measured mass. 383 b: detected only in experiments with simulated sunlight, listed in order from largest to smallest 384 peak areas.

385

386 At the bottom of Table 1, it can be seen that major MS peaks that decreased in size after chamber

387 exposure to methylamine and sunlit clouds (ratios $<1$ ) all have exact masses that match species

388 containing 0 or 1 nitrogen atom per molecule. These species include methylglyoxal dimer and

389 tetramer species (likely formed by aldol condensation) and a proposed imine-organosulfate species 
390 that was present only in experiments where ammonium sulfate was included in seed particles. On

391 the other hand, peaks that increased in size during chamber exposure (Table 1 top) matched

392 molecular formulae with 2 to $7 \mathrm{~N} /$ molecule. Exposure to methylamine in the chamber appears

393 to have increased both methylamine and ammonia incorporation into aqueous-phase products,

394 likely due to methylamine's favorable exchange reaction with dissolved ammonium salts,

395 producing ammonia and methylaminium ions. Calculating an average number of $\mathrm{N} / \mathrm{molecule}$

396 weighted by peak area as described in the SI, we find that chamber exposure of methylglyoxal+AS

397 aerosol to methylamine and sunlit clouds increased the number of nitrogens per detected organic

398 molecule from 1.0 to 2.0, dominated by the production of $\mathrm{C}_{13} \mathrm{H}_{20} \mathrm{~N}_{2} \mathrm{O}_{6}(\mathrm{~m} / z, 301.1410)$ and its

399 incorporation of one methylamine and one ammonia molecule.

400 Unique peaks that were seen only after chamber exposure to methylamine and sunlit clouds were

401 assigned to proposed molecular structures containing 3-6 double bonds, and appear to form from

402 precursors including methylamine, acetaldehyde / acetyl radicals, and/or HA. The formation of

403 the unique $\mathrm{C}_{10} \mathrm{H}_{10} \mathrm{O}_{4} \mathrm{~m} / \mathrm{z} 217.0500$ product also appears to involve oxidation followed by

404 decarboxylation, which can be catalyzed by ammonium salts. ${ }^{71}$ Chamber exposure increased the

405 weighted average number of conjugated double bonds per molecule from 1.0 (non-conjugated) to

4063.0 , again dominated by the production of $\mathrm{C}_{13} \mathrm{H}_{20} \mathrm{~N}_{2} \mathrm{O}_{6}(\mathrm{~m} / \mathrm{z} 301.1410)$ with its four double bonds,

407 three of which are conjugated. In summary, exposure to methylamine, sunlight, and cloud

408 processing results in the conversion of MG oligomers into more conjugated product molecules that

409 incorporate more nitrogen (both methylamine and ammonia) and photolysis products (acetyl

410 radicals and $\mathrm{HA})$.

411 While it was apparent in a recent study that acetyl radicals played a central role in the photo-

412 oligomerization chemistry of methylglyoxal, ${ }^{63}$ the source of these radicals was unclear. Hydration 
413 of methylglyoxal, even in the gas phase, ${ }^{72}$ removes any absorbance bands in the actinic range, ${ }^{73}$

414 suggesting that direct photolysis of aqueous methylglyoxal is unlikely in the atmosphere or in any

415 realistic laboratory simulation. Aqueous solutions of HA, GX, and GAld are less light-absorbing

416 than MG, making direct photolysis of these dissolved compounds even less likely. Once small

417 carbonyl species react with reduced nitrogen compounds in the aqueous phase, however, imines

418 and derivatized $\mathrm{N}$-containing heterocyclic products are formed. ${ }^{74}$ These products are more

419 strongly light absorbing than the reactants, moving absorbance into the actinic range where light

420 absorption can occur. ${ }^{23,25}$ In dark reactions with GX, common atmospheric amines such as glycine

421 and methylamine have been shown to be more effective than ammonium salts at generating C-N

422 bonds $^{66}$ and light-absorbing products. ${ }^{65,66}$ Thus, it is likely that photolysis of first-generation

423 carbonyl + amine BrC products generate the radical species that trigger further oligomerization

424 and brown carbon production.

425 For example, imidazole derivatives are a class of photosensitizer C-N reaction products ${ }^{52,75,76}$

426 that have been detected in aqueous-phase reactions of AS with all four carbonyl compounds used

427 in this study. ${ }^{74}$ Replacing ammonia with primary amines in the dark chemical mechanism

428 produces a permanently charged imidazolium ring whose absorbance is red-shifted by $\sim 10 \mathrm{~nm}$

429 compared to a neutral imidazole ring formed with ammonia. ${ }^{77}$ Additional functional groups

430 attached to the carbon atoms in heterocyclic rings further red-shift the absorbance bands. ${ }^{74}$ The

431 increased overlap of such $\mathrm{N}$-containing reaction products with the solar spectrum is expected to

432 increase production of radicals and excited-state photosensitizer species in the aqueous aerosol

433 phase. In recent $\mathrm{AS}$-free studies of $\mathrm{BrC}$ aerosol formation by methylglyoxal+methylamine

434 reactions, ${ }^{63}$ it was noted that imidazolium derivatives were formed upon exposure to methylamine

435 gas, but then were greatly reduced or eliminated upon exposure to sunlight, suggesting that such 
436 compounds are the source of not only triplet carbon excited state species but also photolysis

437 fragment radicals that trigger further oligomerization and browning in sunlight. This result is

438 consistent with the MS product analysis in Table 1, where N-methyl imidazole species were not

439 detected in aerosol after combined methylamine and sunlight exposure in the chamber.

440 Radical and/or excited state species, once produced, will rapidly react with nearby molecules in

441 crowded aqueous environments, and especially at the air-water interface where surface-active

442 molecules accumulate. ${ }^{78}$ This effect has been noted in bulk aqueous-phase experiments on

443 carbonyl compounds, where oxidation by $\mathrm{OH}$ radicals generated oligomeric products only at high

444 concentrations due to accretion reactions between organic radical intermediates and other organic

445 molecules. ${ }^{79,} 80$ A similar effect is evidently at work in the light-activated formation of brown

446 carbon oligomers in the carbonyl+AS+amine aqueous reaction system. Moreover, the dominance

447 of light-activated radical reaction pathways involving surface-active $\mathrm{BrC}$ may be explain the

448 observed divergent behavior between photobleaching experiments performed in bulk solution and

449 in suspended droplets. ${ }^{50}$

450

451 Acknowledgments. This work was funded by NSF grants AGS-1523178 and AGS-1826593.

452 The CESAM chamber aerosol aging experiments were part of a project that has received funding

453 from the European Union's Horizon 2020 research and innovation program under grant

454 agreement No 730997. CNRS-INSU is gratefully acknowledged for supporting CESAM as an

455 open facility through the National Instrument label, as well as the AERIS data center

456 (https://www.aeris-data.fr/) for hosting, curating, and distributing CESAM chamber data via

457 EUROCHAMP-2020 databases. The HPLCPDA-ESI-HRMS measurements were performed at

458 the Environmental Molecular Sciences Laboratory (EMSL), a national scientific user facility 
459 located at PNNL, and sponsored by the Office of Biological and Environmental Research of the

460 U.S. DOE.

461 Supplemental Information: Description of calculations of peak-weighted $\mathrm{N}$ atoms and

462 conjugated double bonds per detected molecule, additional absorption change graphs,

$463 \mathrm{MG} / \mathrm{GX} / \mathrm{GAld} / \mathrm{HA}+$ methylamine + AS experiment data, effects of acidifying samples with oxalic

464 vs sulfuric acid, data summaries of additional $\mathrm{HOOH}$ addition experiments, and summary table of

465 large chamber aerosol processing experiments.

\section{TOC artwork}

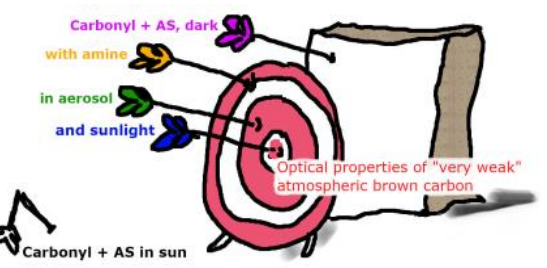


1. Schwartz, J., Air pollution and daily mortality: a review and meta analysis. Environ. Res. 1994, 64, (1), 36-52. doi:10.1006/enrs.1994.1005

2. Schwartz, J., What are people dying of on high air pollution days? Environmental Research 1994, 64, (1), 26-35. doi:10.1006/enrs.1994.1004

3. Kao, A. S.; Friedlander, S. K., Temporal variations of particulate air pollution: a marker for free radical dosage and adverse health effects? Inhal. Toxicol. 1995, 7, (1), 149-156. doi:10.3109/08958379509014278

4. Gilmour, P. S.; Brown, D. M.; Lindsay, T. G.; Beswick, P. H.; MacNee, W.; Donaldson, K., Adverse health effects of PM10 particles: involvement of iron in generation of hydroxyl radical. Occup Environ Med 1996, 53, (12), 817-822. doi:10.1136/oem.53.12.817

5. Harrison, R. M.; Yin, J., Particulate matter in the atmosphere: which particle properties are important for its effects on health? The Science of The Total Environment 2000, 249, (1-3), 85101. doi:10.1016/s0048-9697(99)00513-6

6. Poschl, U., Atmospheric aerosols: Composition, transformation, climate and health effects. Angew Chem Int Edit 2005, 44, (46), 7520-7540. doi:DOI 10.1002/anie.200501122

7. Kennedy, I. M., The health effects of combustion-generated aerosols. Proceedings of the Combustion Institute 2007, 31, 2757-2770. doi:https://doi.org/10.1016/j.proci.2006.08.116

8. Wu, S.; Deng, F.; Wei, H.; Huang, J.; Wang, X.; Hao, Y.; Zheng, C.; Qin, Y.; Lv, H.; Shima, M.; Guo, X., Association of cardiopulmonary health effects with source-appointed ambient fine particulate in Beijing, China: A combined analysis from the Healthy Volunteer Natural Relocation (HVNR) study. Environ Sci Technol 2014, 48, (6), 3438-3448. doi:10.1021/es404778w

9. Ramanathan, V.; Li, F.; Ramana, M. V.; Praveen, P. S.; Kim, D.; Corrigan, C. E.; Nguyen, H.; Stone, E. A.; Schauer, J. J.; Carmichael, G. R.; Adhikary, B.; Yoon, S. C., Atmospheric brown clouds: hemispherical and regional variations in long-range transport, absorption, and radiative forcing. J. Geophys. Res. 2007, 112, (D12), D22S21/1-D22S21/26. doi:10.1029/2006JD008124

10. Bahadur, R.; Praveen, P. S.; Xu, Y.; Ramanathan, V., Solar absorption by elemental and brown carbon determine from spectral observations. Proc. Natl. Acad. Sci. (USA) 2012, 109, (43), 17366-17371. doi:10.1073/pnas.1205910109

11. Feng, Y.; Ramanathan, V.; Kotamarthi, V. R., Brown carbon: a significant atmospheric absorber of solar radiation? Atmos. Chem. Phys. 2013, 13, (17), 8607-8621. doi:10.5194/acp13-8607-2013

12. Laskin, A.; Laskin, J.; Nizkorodov, S. A., Chemistry of Atmospheric Brown Carbon. Chem. Rev. 2015, 115, 4335-4382. doi:10.1021/cr5006167

13. Shamjad, P. M.; Tripathi, S. N.; Pathak, R.; Hallquist, M.; Arola, A.; Bergin, M. H., Contribution of Brown Carbon to Direct Radiative Forcing over the Indo-Gangetic Plain. Environ Sci Technol 2015, 49, (17), 10474-10481. doi:10.1021/acs.est.5b03368

14. Chakrabarty, R. K.; Gyawali, M.; Yatavelli, R. L. N.; Pandey, A.; Watts, A. C.; Knue, J.; Chen, L. W. A.; Pattison, R. R.; Tsibart, A.; Samburova, V.; Moosmüller, H., Brown carbon aerosols from burning of boreal peatlands: microphysical properties, emission factors, and implications for direct radiative forcing. Atmos. Chem. Phys. 2016, 16, (5), 3033-3040. doi:10.5194/acp16-3033-2016 
513

514

515

516

517

518

519

520

521

522

523

524

525

526

527

528

529

530

531

532

533

534

535

536

537

538

539

540

541

542

543

544

545

546

547

548

549

550

551

552

553

554

555

556

557

15. Zhang, Y.; Forrister, H.; Liu, J.; Dibb, J.; Anderson, B.; Schwarz, J. P.; Perring, A. E.; Jimenez, J. L.; Campuzano-Jost, P.; Wang, Y.; Nenes, A.; Weber, R. J., Top-of-atmosphere radiative forcing affected by brown carbon in the upper troposphere. Nature Geosci. 2017, 10, 486-489. doi:10.1038/ngeo2960

16. Brown, H.; Liu, X.; Feng, Y.; Jiang, Y.; Wu, M.; Lu, Z.; Wu, C.; Murphy, S.; Pokhrel, R., Radiative effect and climate impacts of brown carbon with the Community Atmosphere Model (CAM5). Atmos. Chem. Phys. 2018, 18, (24), 17745-17768. doi:10.5194/acp-18-17745-2018

17. Zhang, A.; Wang, Y.; Zhang, Y.; Weber, R. J.; Song, Y.; Ke, Z.; Zou, Y., Modeling global radiative effect of brown carbon: A larger heating source in the tropical free troposphere than black carbon. Atmos. Chem. Phys. Discuss. 2019, 2019, 1-36. doi:10.5194/acp-2019-594

18. Tuccella, P.; Curci, G.; Pitari, G.; Lee, S.; Jo, D. S., Direct radiative effect of absorbing aerosols: sensitivity to mixing state, brown carbon and soil dust refractive index and shape. Journal of Geophysical Research: Atmospheres 2020, 125, (2), e2019JD030967. doi:10.1029/2019JD030967

19. Mukai, H.; Ambe, Y., Characterization of a humic acid-like brown substance in airborne particulate matter and tentative identification of its origin. Atmospheric Environment (1967) 1986, 20, (5), 813-819. doi:https://doi.org/10.1016/0004-6981(86)90265-9

20. Hecobian, A.; Zhang, X.; Zheng, M.; Frank, N.; Edgerton, E. S.; Weber, R. J., Water-soluble organic aerosol material and the light-absorption characteristics of aqueous extracts measured over the southeastern United States. Atmos. Chem. Phys. 2010, 10, 5965-5977. doi:10.5194/acp-10-5965-2010

21. Noziere, B.; Dziedzic, P.; Cordova, A., Formation of secondary light-absorbing "fulvic-like" oligomers: a common process in aqueous and ionic atmospheric particles? Geophys. Res. Lett. 2007, 34, L21812. doi:10.1029/2007GL031300

22. Galloway, M. M.; Chhabra, P. S.; Chan, A. W. H.; Surratt, J. D.; Flagan, R. C.; Seinfeld, J. H.; Keutsch, F. N., Glyoxal uptake on ammonium sulphate seed aerosol: reaction products and reversibility of uptake under dark and irradiated conditions. Atmos. Chem. Phys. 2009, 9, 33313345. doi:10.5194/acp-9-3331-2009

23. Shapiro, E. L.; Szprengiel, J.; Sareen, N.; Jen, C. N.; Giordano, M. R.; McNeill, V. F., Lightabsorbing secondary organic material formed by glyoxal in aqueous aerosol mimics. Atmos. Chem. Phys. 2009, 9, 2289-2300. doi:10.5194/acp-9-2289-2009

24. Yasmeen, F.; Sauret, N.; Gal, J. F.; Maria, P. C.; Massi, L.; Maenhaut, W.; Claeys, M., Characterization of oligomers from methylglyoxal under dark conditions: a pathway to produce secondary organic aerosol through cloud processing during nighttime. Atmos. Chem. Phys. 2010, 10, (8), 3803-3812. doi:10.5194/acp-10-3803-2010

25. Sareen, N.; Schwier, A. N.; Shapiro, E. L.; Mitroo, D.; McNeill, V. F., Secondary organic material formed by methylglyoxal in aqueous aerosol mimics. Atmos. Chem. Phys. 2010, 10, 997-1016. doi:10.5194/acp-10-997-2010

26. Hawkins, L. N.; Lemire, A. N.; Galloway, M. M.; Corrigan, A. L.; Turley, J. J.; Espelien, B. M.; De Haan, D. O., Maillard Chemistry in Clouds and Aqueous Aerosol As a Source of Atmospheric Humic-Like Substances. Environ Sci Technol 2016, 50, 7443-7452. doi:10.1021/acs.est.6b00909

27. Gao, Y.; Zhang, Y., Formation and photochemical investigation of brown carbon by hydroxyacetone reactions with glycine and ammonium sulfate. $R S C A d v . \mathbf{2 0 1 8}, 8$, (37), 2071920725. doi:10.1039/C8RA02019A 
28. Noziere, B.; Cordova, A., A kinetic and mechanistic study of the amino acid catalyzed aldol condensation of acetaldehyde in aqueous and salt solutions. J. Phys. Chem. 2008, 112, (13), 2827-2837. doi:10.1021/jp7096845

29. Altieri, K. E.; Seitzinger, S. P.; Carlton, A. G.; Turpin, B. J.; Klein, G. C.; Marshall, A. G., Oligomers formed through in-cloud methylglyoxal reactions: chemical composition, properties, and mechanisms investigated by ultra-high resolution FT-ICR mass spectrometry. Atmos. Environ. 2008, 42, 1476-1490. doi:10.1016/j.atmosenv.2007.11.015

30. Kampf, C. J.; Jakob, R.; Hoffmann, T., Identification and characterization of aging products in the glyoxal/ammonium sulfate system -- implications for light-absorbing material in atmospheric aerosols. Atmos. Chem. Phys. 2012, 12, 6323-6333. doi:10.5194/acp-12-63232012

31. Lin, P.; Laskin, J.; Nizkorodov, S. A.; Laskin, A., Revealing Brown Carbon Chromophores Produced in Reactions of Methylglyoxal with Ammonium Sulfate. Environ Sci Technol 2015, 49, (24), 14257-14266. doi:10.1021/acs.est.5b03608

32. De Haan, D. O.; Hawkins, L. N.; Welsh, H. G.; Pednekar, R.; Casar, J. R.; Pennington, E. A.; de Loera, A.; Jimenez, N. G.; Symons, M. A.; Zauscher, M.; Pajunoja, A.; Caponi, L.; Cazaunau, M.; Formenti, P.; Gratien, A.; Pangui, E.; Doussin, J. F., Brown carbon production in ammonium- or amine-containing aerosol particles by reactive uptake of methylglyoxal and photolytic cloud cycling. Environmental Science \& Technology 2017, in press. doi:10.1021/acs.est.7b00159

33. Hawkins, L. N.; Welsh, H. G.; Alexander, M. V., Evidence for pyrazine-based chromophores in cloud water mimics containing methylglyoxal and ammonium sulfate. Atmos. Chem. Phys. 2018, 18, (16), 12413-12431. doi:10.5194/acp-18-12413-2018

34. Chang, J. L.; Thompson, J. E., Characterization of colored products formed during irradiation of solutions containing $\mathrm{H}_{2} \mathrm{O}_{2}$ and phenolic compounds. Atmos. Environ. 2010, 44, 541-551. doi:10.1016/j.atmosenv.2009.10.042

35. Ofner, J.; Krüger, H. U.; Grothe, H.; Schmitt-Kopplin, P.; Whitmore, K.; Zetzsch, C., Physicochemical characterization of SOA derived from catechol and guaiacol - a model substance for the aromatic fraction of atmospheric HULIS. Atmos. Chem. Phys. 2011, 11, (1), 1-15. doi:10.5194/acp-11-1-2011

36. Yu, L.; Smith, J.; Laskin, A.; Anastasio, C.; Laskin, J.; Zhang, Q., Chemical characterization of SOA formed from aqueous-phase reactions of phenols with the triplet excited state of carbonyl and hydroxyl radical. Atmos. Chem. Phys. 2014, 14, (24), 13801-13816, 16 pp. doi:10.5194/acp-14-13801-2014

37. Yu, L.; Smith, J.; Laskin, A.; George, K. M.; Anastasio, C.; Laskin, J.; Dillner, A. M.; Zhang, Q., Molecular transformations of phenolic SOA during photochemical aging in the aqueous phase: competition among oligomerization, functionalization, and fragmentation. Atmos. Chem. Phys. 2016, 16, (7), 4511-4527. doi:10.5194/acp-16-4511-2016

38. Smith, J. D.; Kinney, H.; Anastasio, C., Phenolic carbonyls undergo rapid aqueous photodegradation to form low-volatility, light-absorbing products. Atmos. Environ. 2016, 126, 36-44. doi:http://dx.doi.org/10.1016/j.atmosenv.2015.11.035

39. Xu, J.; Cui, T.; Fowler, B.; Fankhauser, A.; Yang, K.; Surratt, J. D.; McNeill, V. F., Aerosol Brown Carbon from Dark Reactions of Syringol in Aqueous Aerosol Mimics. ACS Earth and Space Chemistry 2018, 2, (6), 608-617. doi:10.1021/acsearthspacechem.8b00010

40. Vione, D.; Albinet, A.; Barsotti, F.; Mekic, M.; Jiang, B.; Minero, C.; Brigante, M.; Gligorovski, S., Formation of substances with humic-like fluorescence properties, upon 
604

605

606

607

608

609

610

611

612

613

614

615

616

617

618

619

620

621

622

623

624

625

626

627

628

629

630

631

632

633

634

635

636

637

638

639

640

641

642

643

644

645

646

647

648

photoinduced oligomerization of typical phenolic compounds emitted by biomass burning. Atmos. Environ. 2019, 206, 197-207. doi:https://doi.org/10.1016/j.atmosenv.2019.03.005

41. Lavi, A.; Lin, P.; Bhaduri, B.; Carmieli, R.; Laskin, A.; Rudich, Y., Characterization of LightAbsorbing Oligomers from Reactions of Phenolic Compounds and Fe(III). ACS Earth and Space Chemistry 2017. doi:10.1021/acsearthspacechem.7b00099

42. Al Nimer, A.; Rocha, L.; Rahman, M. A.; Nizkorodov, S. A.; Al-Abadleh, H. A., Effect of Oxalate and Sulfate on Iron-Catalyzed Secondary Brown Carbon Formation. Environ Sci Technol 2019, 53, (12), 6708-6717. doi:10.1021/acs.est.9b00237

43. Link, N.; Removski, N.; Yun, J.; Fleming, L. T.; Nizkorodov, S. A.; Bertram, A. K.; AlAbadleh, H. A., Dust-Catalyzed Oxidative Polymerization of Catechol and Its Impacts on Ice Nucleation Efficiency and Optical Properties. ACS Earth and Space Chemistry 2020. doi:10.1021/acsearthspacechem.0c00107

44. De Haan, D. O.; Hawkins, L. N.; Tolbert, M. A.; Doussin, J. F., Glyoxal's impact on dry ammonium salts: fast and reversible surface aerosol browning (Raw Data). Chemistry and Biochemistry: Faculty Scholarship (Digital Repository) 2020, (40). doi:https://doi.org/10.22371/02.2020.006

45. Lee, H. J.; Aiona, P. K.; Laskin, A.; Laskin, J.; Nizkorodov, S. A., Effect of solar radiation on the optical properties and molecular composition of laboratory proxies of atmospheric brown carbon. Environ. Sci. Technol. 2014, 48, (17), 10217-10226. doi:10.1021/es502515r

46. Dasari, S.; Andersson, A.; Bikkina, S.; Holmstrand, H.; Budhavant, K.; Satheesh, S.; Asmi, E.; Kesti, J.; Backman, J.; Salam, A.; Bisht, D. S.; Tiwari, S.; Hameed, Z.; Gustafsson, Ö., Photochemical degradation affects the light absorption of water-soluble brown carbon in the South Asian outflow. Science Advances 2019, 5, (1), eaau8066. doi:10.1126/sciadv.aau8066

47. O'Brien, R. E.; Kroll, J. H., Photolytic Aging of Secondary Organic Aerosol: Evidence for a Substantial Photo-Recalcitrant Fraction. The Journal of Physical Chemistry Letters 2019, 10, (14), 4003-4009. doi:10.1021/acs.jpclett.9b01417

48. Browne, E. C.; Zhang, X.; Franklin, J. P.; Ridley, K. J.; Kirchstetter, T. W.; Wilson, K. R.; Cappa, C. D.; Kroll, J. H., Effect of heterogeneous oxidative aging on light absorption by biomass-burning organic aerosol. Aerosol Sci. Technol. 2019, 1-15. doi:10.1080/02786826.2019.1599321

49. Fleming, L. T.; Lin, P.; Roberts, J. M.; Selimovic, V.; Yokelson, R.; Laskin, J.; Laskin, A.; Nizkorodov, S. A., Molecular composition and photochemical lifetimes of brown carbon chromophores in biomass burning organic aerosol. Atmos. Chem. Phys. 2020, 20, (2), 11051129. doi:10.5194/acp-20-1105-2020

50. Jones, S. H.; Friederich, P.; Donaldson, D. J., Photochemical Aging of Levitated Aqueous Brown Carbon Droplets. ACS Earth and Space Chemistry 2021. doi:10.1021/acsearthspacechem.1c00005

51. Chen, L.-W. A.; Chow, J. C.; Wang, X.; Cao, J.; Mao, J.; Watson, J. G., Brownness of Organic Aerosol over the United States: Evidence for Seasonal Biomass Burning and Photobleaching Effects. Environ Sci Technol 2021. doi:10.1021/acs.est.0c08706

52. Rossignol, S.; Aregahegn, K. Z.; Tinel, L.; Fine, L.; Noziere, B.; George, C., Glyoxal Induced Atmospheric Photosensitized Chemistry Leading to Organic Aerosol Growth. Environ. Sci. Technol. 2014, 48, (6), 3218-3227. doi:10.1021/es405581g

53. Chen, Q.; Mu, Z.; Xu, L.; Wang, M.; Wang, J.; Shan, M.; Fan, X.; Song, J.; Wang, Y.; Lin, P.; $\mathrm{Du}, \mathrm{L}$., Triplet-state organic matter in atmospheric aerosols: Formation characteristics and 
potential effects on aerosol aging. Atmos. Environ. 2021, 252, 118343. doi:https://doi.org/10.1016/j.atmosenv.2021.118343

54. Jiang, W.; Misovich, M. V.; Hettiyadura, A. P. S.; Laskin, A.; McFall, A. S.; Anastasio, C.; Zhang, Q., Photosensitized Reactions of a Phenolic Carbonyl from Wood Combustion in the Aqueous Phase-Chemical Evolution and Light Absorption Properties of AqSOA. Environ Sci Technol 2021. doi:10.1021/acs.est.0c07581

55. Zhao, R.; Lee, A. K. Y.; Abbatt, J. P. D., Investigation of Aqueous-Phase Photooxidation of Glyoxal and Methylglyoxal by Aerosol Chemical Ionization Mass Spectrometry: Observation of Hydroxyhydroperoxide Formation. The Journal of Physical Chemistry A 2012, 116, (24), 6253-6263. doi:10.1021/jp211528d

56. Sareen, N.; Moussa, S. G.; McNeill, V. F., Photochemical Aging of Light-Absorbing Secondary Organic Aerosol Material. The Journal of Physical Chemistry A 2013, 117, (14), 2987-2996. doi:10.1021/jp309413j

57. Zhao, R.; Lee, A. K. Y.; Huang, L.; Li, X.; Yang, F.; Abbatt, J. P. D., Photochemical processing of aqueous atmospheric brown carbon. Atmos. Chem. Phys. 2015, 15, (11), 6087-6100. doi:10.5194/acp-15-6087-2015

58. Aiona, P. K.; Lee, H. J.; Leslie, R.; Lin, P.; Laskin, A.; Laskin, J.; Nizkorodov, S. A., Photochemistry of Products of the Aqueous Reaction of Methylglyoxal with Ammonium Sulfate. ACS Earth and Space Chemistry 2017, 1, (8), 522-532. doi:10.1021/acsearthspacechem.7b00075

59. Vo, L.; Legaard, E.; Thrasher, C.; Jaffe, A.; Berden, G.; Martens, J.; Oomens, J.; O’Brien, R. E., UV/Vis and IRMPD Spectroscopic Analysis of the Absorption Properties of Methylglyoxal Brown Carbon. ACS Earth and Space Chemistry 2021, 5, (4), 910-919. doi:10.1021/acsearthspacechem.1c00022

60. Wong, J. P. S.; Nenes, A.; Weber, R. J., Changes in Light Absorptivity of Molecular Weight Separated Brown Carbon Due to Photolytic Aging. Environ Sci Technol 2017, 51, (15), 84148421. doi:10.1021/acs.est.7b01739

61. He, Q.; Tomaz, S.; Li, C.; Zhu, M.; Meidan, D.; Riva, M.; Laskin, A.; Brown, S. S.; George, C.; Wang, X.; Rudich, Y., Optical Properties of Secondary Organic Aerosol Produced by Nitrate Radical Oxidation of Biogenic Volatile Organic Compounds. Environ Sci Technol 2021. doi:10.1021/acs.est.0c06838

62. Wang, J.; Doussin, J. F.; Perrier, S.; Perraudin, E.; Katrib, Y.; Pangui, E.; Picquet-Varrault, B., Design of a new multi-phase experimental simulation chamber for atmospheric photosmog, aerosol and cloud chemistry research. Atmos. Meas. Tech. 2011, 4, 2465-2494. doi:10.5194/amt-4-2465-2011

63. De Haan, D. O.; Tapavicza, E.; Riva, M.; Cui, T.; Surratt, J.; Smith, A. C.; Jordan, M.-C.; Nilakantan, S.; Almodovar, M.; Stewart, T. N.; de Loera, A.; De Haan, A. C.; Cazaunau, M.; Gratien, A.; Pangui, E.; Doussin, J. F., Nitrogen-containing, light-absorbing oligomers produced in aerosol particles exposed to methylglyoxal, photolysis, and cloud cycling. Environ. Sci. Technol. 2018, 52, (7), 4061-4071. doi:10.1021/acs.est.7b06105

64. Lin, P.; Fleming, L. T.; Nizkorodov, S. A.; Laskin, J.; Laskin, A., Comprehensive Molecular Characterization of Atmospheric Brown Carbon by High Resolution Mass Spectrometry with Electrospray and Atmospheric Pressure Photoionization. Anal. Chem. 2018, 90, (21), 1249312502. doi:10.1021/acs.analchem.8b02177 
693

694

695

696

697

698

699

700

701

702

703

704

705

706

707

708

709

710

711

712

713

714

715

716

717

718

719

720

721

722

723

724

725

726

727

728

729

730

731

732

733

734

735

736

737

738
65. Powelson, M. H.; Espelien, B. M.; Hawkins, L. N.; Galloway, M. M.; De Haan, D. O., Brown carbon formation by aqueous-phase aldehyde reactions with amines and ammonium sulfate. Environ Sci Technol 2014, 48, (2), 985-993. doi:10.1021/es4038325

66. Trainic, M.; Riziq, A. A.; Lavi, A.; Rudich, Y., Role of interfacial water in the heterogeneous uptake of glyoxal by mixed glycine and ammonium sulfate aerosols. Journal of Physical Chemistry A 2012, 116, 5948-5957. doi:10.1021/jp2104837

67. Drozd, G. T.; McNeill, V. F., Organic matrix effects on the formation of light-absorbing compounds from [small alpha]-dicarbonyls in aqueous salt solution. Environmental Science: Processes \& Impacts 2014, 16, (4), 741-747. doi:10.1039/C3EM00579H

68. Gómez Alvarez, E.; Wortham, H.; Strekowski, R.; Zetzsch, C.; Gligorovski, S., Atmospheric Photosensitized Heterogeneous and Multiphase Reactions: From Outdoors to Indoors. Environ Sci Technol 2012, 46, (4), 1955-1963. doi:10.1021/es2019675

69. Saleh, R., From Measurements to Models: Toward Accurate Representation of Brown Carbon in Climate Calculations. Current Pollution Reports 2020, 6, (2), 90-104. doi:10.1007/s40726020-00139-3

70. Pospisilova, V.; Bell, D. M.; Lamkaddam, H.; Bertrand, A.; Wang, L.; Bhattu, D.; Zhou, X.; Dommen, J.; Prevot, A. S. H.; Baltensperger, U.; El Haddad, I.; Slowik, J. G., Photodegradation of $\alpha$-Pinene Secondary Organic Aerosol Dominated by Moderately Oxidized Molecules. Environ Sci Technol 2021. doi:10.1021/acs.est.0c06752

71. Klodt, A. L.; Zhang, K.; Olsen, M. W.; Fernandez, J. L.; Furche, F.; Nizkorodov, S. A., Effect of Ammonium Salts on the Decarboxylation of Oxaloacetic Acid in Atmospheric Particles. ACS Earth and Space Chemistry 2021, 5, (4), 931-940. doi:10.1021/acsearthspacechem.1c00025

72. Axson, J. L.; Takahashi, K.; De Haan, D. O.; Vaida, V., Gas-phase water-mediated equilibrium between methylglyoxal and its geminal diol. P. Natl. Acad. Sci. USA 2010, 107, (15), 66876692. doi:10.1073/pnas.0912121107

73. Kroll, J. A.; Hansen, A. S.; Møller, K. H.; Axson, J. L.; Kjaergaard, H. G.; Vaida, V., Ultraviolet Spectroscopy of the Gas Phase Hydration of Methylglyoxal. ACS Earth and Space Chemistry 2017, 1, (6), 345-352. doi:10.1021/acsearthspacechem.7b00054

74. Grace, D. N.; Sharp, J. R.; Holappa, R. E.; Lugos, E. N.; Sebold, M. B.; Griffith, D. R.; Hendrickson, H. P.; Galloway, M. M., Heterocyclic Product Formation in Aqueous Brown Carbon Systems. ACS Earth and Space Chemistry 2019, 3, (11), 2472-2481. doi:10.1021/acsearthspacechem.9b00235

75. Aregahegn, K. Z.; Noziere, B.; George, C., Organic aerosol formation photo-enhanced by the formation of secondary photosensitizers in aerosols. Faraday Discuss. 2013, 165, 123-134. doi:10.1039/c3fd00044c

76. Teich, M.; van Pinxteren, D.; Kecorius, S.; Wang, Z.; Herrmann, H., First quantification of imidazoles in ambient aerosol particles: Potential photosensitizers, brown carbon constituents, and hazardous components. Environ Sci Technol 2016, 50, 1166-1173. doi:10.1021/acs.est.5b05474

77. Zhu, Y.; Xiao, L.; Zhao, M.; Zhou, J.; Zhang, Q.; Wang, H.; Li, S.; Zhou, H.; Wu, J.; Tian, Y., A Series of Imidazole Derivatives: Synthesis, Two-Photon Absorption, and Application for Bioimaging. BioMed Research International 2015, 2015, 965386. doi:10.1155/2015/965386

78. Frka, S.; Dautović, J.; Kozarac, Z.; Ćosović, B.; Hoffer, A.; Kiss, G., Surface-active substances in atmospheric aerosol: an electrochemical approach. Tellus B: Chemical and Physical Meteorology 2012, 64, (1), 18490. doi:10.3402/tellusb.v64i0.18490 
739

740

741

742

743

744

745

746
79. Tan, Y.; Lim, Y. B.; Altieri, K. E.; Seitzinger, S. P.; Turpin, B. J., Mechanisms leading to oligomers and SOA through aqueous photooxidation: insights from $\mathrm{OH}$ radical oxidation of acetic acid and methylglyoxal. Atmos. Chem. Phys. 2012, 12, 801-813. doi:10.5194/acp-12801-2012

80. Tan, Y.; Perri, M. J.; Seitzinger, S. P.; Turpin, B. J., Effects of precursor concentration and acidic sulfate in aqueous glyoxal - $\mathrm{OH}$ radical oxidation and implications for secondary organic aerosol. Environ. Sci. Technol. 2009, 43, (21), 8105-8112. doi:10.1021/es901742f 